\title{
Direct anti-proliferative effect of adipose-derived mesenchymal stem cells of ankylosing spondylitis patients on allogenic CD4+ cells
}

\author{
Ewa Kuca-Warnawin ${ }^{1}$ ID , Magdalena Plebańczyk ${ }^{1}$ ID , Krzysztof Bonek², Ewa Kontny $^{1}$ ID \\ ${ }^{1}$ Department of Pathophysiology and Immunology, National Institute of Geriatrics, Rheumatology and Rehabilitation, Warsaw, Poland \\ ${ }^{2}$ Clinic of Rheumatology, National Institute of Geriatrics, Rheumatology and Rehabilitation, Warsaw, Poland
}

\begin{abstract}
Objectives: T-cell-mediated adaptive immunity contributes to the development and persistence of ankylosing spondylitis (AS). Mesenchymal stromal/stem cells (MSCs) have immunomodulatory potential and are able to inhibit T-cell proliferation, but their functionality in AS patients is relatively unknown. The aim of the study was to assess the direct anti-proliferative effects of MSCs isolated from subcutaneous abdominal adipose tissue of AS patients (AS/ASCS) on allogeneic T lymphocytes, using commercially available ASC lines from healthy donors (HD/ASCs) as a control.

Material and methods: CD3+CD4+ T-cells were isolated from peripheral blood of healthy blood donors, activated with anti-CD3/CD28 beads, and co-cultured for 5 days with untreated and TNF+IFN- $\gamma$ pre-stimulated HD/ASCs (5 cell lines) and AS/ASCs, obtained from 11 patients (6F/5M). The proliferative response of T-cells was analysed by flow cytometry, while the concentrations of kynurenines, prostaglandin E2 (PGE-2), interleukin 10 (IL-10), and interleukin 1 receptor antagonist (IL-1Ra) were measured spectrophotometrically or using a specific enzyme-linked immunosorbent assay (ELISA). Results: HD/ASCs and AS/ASCs similarly reduced the T-cell proliferation response, i.e. the percentage of proliferating cells, the proliferation, and replication indices, and these effects were dependent mostly on soluble factors. In the co-cultures of activated CD4+ T-cells with HD/ASCs and AS/ASCs significant increases of kynurenines, PGE-2, and IL-1Ra, but not IL-10, production were observed. The release of these factors was dependent either on cell-to-cell contact (IL-10, IL-1Ra) or soluble factors (kynurenines, PGE-2). There was a moderate to strong negative correlation between T-cell proliferative response, and the concentrations of kynurenines, PGE-2, and IL-10, but not IL-1Ra. This association was more evident in the case of TI-treated AS/ASCs than HD/ASCs.

Conclusions: AS/ASCs, similar to HD/ASCs, exert a direct effective anti-proliferative impact on CD4+ $T$ cells, acting via soluble factors that are released in cell contact-dependent (IL-10) and independent (kynurenines, PGE-2) pathways. Thus, our results suggest that AS/ASCs are potentially useful for therapeutic application.
\end{abstract}

Key words: ankylosing spondylitis, adipose-derived mesenchymal stem cells, T-cell proliferation, kynurenines.

\section{Introduction}

Ankylosing spondylitis (AS), characterized by chronic inflammation and pathological new bone formation at axial joints, is thought to develop and persist due to aberrant immune reactions at sites of mechanical stress and interactions between innate and adaptive immune mechanisms [1].
The association of AS with HLA-B27 and endoplasmic reticulum aminopeptidases (ERAP) encoding alleles points to antigen presentation and T-cell-mediated adaptive immunity as critical contributors to disease pathology [2, 3].

This is supported by reports showing numerous T-cells infiltrating affected joints in early and active sacroiliitis 
$[4,5]$ along with an increased number and greater proliferation of CD4+ and CD8+ T-cells in synovial fluid and peripheral blood of AS patients [6-9].

Mesenchymal stromal/stem cells (MSCs) possess immunomodulatory potential and, among other abilities, can inhibit proliferation of T-cells $[10,11]$ and decrease the level of proinflammatory cytokines [12].

However, their functionality in AS patients is relatively unknown. Scarce data indicate aberrant functions and reduced immunomodulatory potential of bone marrow-derived MSCS (BM-MSCS) [13-15].

Moreover, we have previously found that adipose tissue-derived MSCS (ASCS) of AS patients (AS/ASCS) show certain abnormalities in the expression of surface markers and secretory activity [16]. Thus, it is possible that immunomodulatory capabilities of these cells may also be impaired.

To clarify this, we presently assessed direct anti-proliferative effects of AS/ASCS on allogeneic $T$ lymphocytes, using ASCs from healthy donors (HD/ASCS) as a control.

To this aim, the proliferation of purified activated CD4+ T-cells co-cultured with ASCs was evaluated by several indices, and the contribution of soluble factors, i.e. kynurenines, prostaglandin E2 (PGE-2), interleukin 10 (IL-10), and interleukin 1 receptor antagonist (IL-1Ra), to ASCs-triggered effects was also analysed.

\section{Material and methods}

\section{Patients, sample collection, and ethics approval}

A group of 11 patients ( 6 female, 5 male) who fulfilled the Assessment of SpondyloArthritis International Society (ASAS) criteria for AS [17] were included in the study. Demographic and clinical characteristics of the patients are presented in Table I.

This study meets all criteria contained in the Declaration of Helsinki and was approved by the Ethics Committee of the National Institute of Geriatrics, Rheumatology, and Rehabilitation, Warsaw, Poland (approval protocol no: KBT-8/4/20016). All patients gave their written informed consent prior to enrolment.

\section{Adipose tissue-derived mesenchymal stem cell isolation and culture}

Specimens of subcutaneous abdominal fat were taken from the patients by $18 \mathrm{G}$ needle biopsy. Tissue processing, ASC isolation and culture were performed as described previously [18]. Five human adipose-derived mesenchymal cell lines (Lonza Group, Lonza Walkersville Inc., MD, USA) were used as a control.
Table I. Demographic and clinical characteristics of patients

\begin{tabular}{|lc|}
\hline $\begin{array}{l}\text { Parameters } \\
(n=11)\end{array}$ & $\begin{array}{c}\text { Ankylosing spondylitis } \\
\text { Demographics }\end{array}$ \\
\hline $\begin{array}{l}\text { Age, years } \\
\text { Gender, female/male, } n\end{array}$ & $51.5(25-70)$ \\
\hline Disease duration, years & $5(1.5-17.0)$ \\
\hline Clinical data & $6.75(1-8.2)$ \\
\hline BASDAl, score & $3.85(1.5-4.3)$ \\
\hline ASDASCRP, score & $6.7(0-9.60)$ \\
\hline BASFI, score & $5.2(1-7.2)$ \\
\hline BASMI, score & $1.125(0-2.75)$ \\
\hline HAO, score & $7.5(5-50)$ \\
\hline Laboratory values & $17(1-59)$ \\
\hline CRP, mg/l & 60 \\
\hline ESR, mm/h & 30 \\
\hline Medications & 20 \\
\hline NSAIDs, \% & \\
\hline Non-biologic DMARDs, \% & \\
\hline Glucocorticosteroids, \% & \\
\hline
\end{tabular}

Except where indicated otherwise, values are the median (range). ASDAS - Ankylosing Spondylitis Disease Activity Score, BASDAI - Bath Ankylosing Spondylitis Disease Activity Index, BASFI - Bath Ankylosing Spondylitis Functional Index, BASMI - Bath Ankylosing Spondylitis Metrology Index, CRP - C-reactive protein, DMARDs - disease-modifying anti-rheumatic drugs, ESR - erythrocyte sedimentation rate, HAQ - Health Assessment Questionnaire, NSAIDs - non-steroid anti-inflammatory drugs.

All experiments were performed using ASCs at 3-5 passages. Adipose tissue-derived mesenchymal stem cells were cultured in complete culture medium composed of DMEM/F12 (PAN Biotech United Kingdom Ltd., Wimborne, UK), 10\% fetal calf serum (FCS) (Biochrom, Berlin, Germany), $200 \mathrm{U} / \mathrm{ml}$ penicillin, $200 \mu \mathrm{g} / \mathrm{ml}$ streptomycin (Polfa Tarchomin S.A., Warsaw, Poland) and $5 \mu \mathrm{g} / \mathrm{ml}$ Plasmocin (InvivoGen, San Diego, CA, USA).

Both untreated and cytokine pre-stimulated ASCs were applied. For pre-stimulation, ASC s were cultured for 24 hours with human recombinant tumour necrosis factor (TNF) and interferon gamma (IFN- $\gamma$ ) (both from R\&D Systems, Minneapolis, MN, USA; each applied at $10 \mathrm{ng} / \mathrm{ml}$ ).

\section{Co-culture of adipose tissue-derived mesenchymal stem cells with purified allogeneic CD4+ T-cells}

Peripheral blood mononuclear cells (PBMCs) were isolated from buffy coats obtained from healthy male honorary blood donors ( $<60$ years old), according to the routinely applied procedure using Ficoll-Paque (GE 
Healthcare, Uppsala, Sweden). The CD3+CD4+ cells were isolated from PBMCs using the EasySep Human CD4+ T-Cell Isolation Kit (Stemcell Technologies, Vancouver, Canada).

After isolation, CD4+ T-cells $\left(1.2 \times 10^{6} /\right.$ well/ $2 \mathrm{ml}$ of medium) were seeded either directly (contacting cultures) or on $0.4 \mathrm{~mm}$ pore size Transwell filters (MD24 with carrier for inserts 0.4 MY, Thermo Fisher Scientific, Massachusetts, MA, USA) (non-contacting co-culture) into 24-well plates with adherent ASCs $\left(5 \times 10^{4} /\right.$ well/2 ml of medium), then T-cells were activated with Dynabeads Human T-Activator CD3/CD28 (Thermo Fisher Scientific, Massachusetts, MA, USA).

After 5 days of co-culture, CD4+ T-cells and culture supernatants were harvested for further analysis, i.e. flow cytometry to identify proliferating and non-proliferating cells, and the measurement of concentrations of kynurenines, PGE-2, IL-10, and IL-1Ra, respectively. The CD4+ T-cells cultured separately were used as a control.

\section{Proliferation assay}

For proliferation assay, purified CD3+CD4+ T lymphocytes were stained with carboxyfluorescein diacetate succinimidyl ester (CFSE) or cell trace violet (CTV) (Thermo Fisher Scientific, Massachusetts, MA, USA), then co-cultured with ASCs as described above.

Cells harvested from cultures were analysed by flow cytometry to identify proliferating and non-proliferating cells. To characterize the cellular proliferation response, the percentage of proliferating cells, proliferation index (PI - number of division per proliferating cell), and replication index (RI - fold expansion) were calculated as described elsewhere [19].

\section{Measurement of soluble factor concentrations in culture supernatants}

The concentration of PGE-2 was measured using the Parameter Kit (R\&D Systems, Minneapolis, MN). Kynurenine concentration was measured spectrophotometrically as described previously [16].

To this aim, culture supernatants were mixed with $30 \%$ trichloroacetic acid at a $2: 1$ ratio and incubated for $30 \mathrm{~min}$ at $5^{\circ} \mathrm{C}$, then centrifuged at $10000 \times \mathrm{g}$ for 5 min and finally diluted at a 1: 1 ratio in Ehrlich's reagent (100 mg of p-dimethyl benzaldehyde and $5 \mathrm{ml}$ of glacial acetic acid; Sigma-Aldrich, St. Louis, MO, USA).

The optical density of the samples was measured at a wavelength of $490 \mathrm{~nm}$. L-kynurenine (Sigma-Aldrich, St. Louis, MO, USA) diluted in culture medium was used to prepare the standard curve. The concentrations of cytokines were measured by specific enzyme-linked immunosorbent assays (ELISAs), i.e. IL-1Ra using ELISA
DuoSet Kits from R\&D Systems, and IL-10 using human IL-10 ELISA (cat. no. 88-7104-88) from Invitrogen (Vienna, Austria). All measurements were taken in duplicate.

\section{Data analyses}

Data were analysed using GraphPad Prism software version 7. The Shapiro-Wilk test was used as a normality test. The Wilcoxon test was applied to compare the secretion of soluble factors by resting and activated CD4+ T-cells.

One-way analysis of variance (ANOVA) with repeated measures and the post-hoc Tukey test were used to assess the effect of untreated and TNF/IFN- $\gamma(\mathrm{TI})$-treated ASCS $\left(\mathrm{ASCS}_{\mathrm{Tl}}\right)$ on target cells, as well as to compare contacting versus (vs) non-contacting co-cultures.

The Mann-Whitney test was applied to analyse differences between effects exerted by ASCs of healthy donors versus ASCs of ankylosing spondylitis patients. Parametric (Pearson's linear) and non-parametric (Spearman's rank) correlation tests were used to assess associations between analysed parameters. Probability values less than 0.05 were considered significant.

\section{Results}

\section{Patients}

The patient cohort was heterogenous with respect to demographic and clinical data (Table I). All patients were HLA-B27 positive, 50\% of them presented ocular symptoms (iritis), and none of them had peripheral arthritis. They were mostly treated with non-steroid anti-inflammatory drugs (NSAIDs), while application of non-biologic disease-modifying anti-rheumatic drugs (DMARDs) and glucocorticosteroids was less frequent.

\section{Inhibition of T-cell proliferation by adipose tissue-derived mesenchymal stem cells}

In control, separately cultured, purified CD4+ T-cells activated via the CD3/CD28 pathway the majority of cells proliferated (mean \pm SEM $=63.9 \pm 3.4 \%$ ).

In the presence of both untreated and TI-stimulated ASCs, the number of proliferating T-cells decreased significantly. The number of proliferating CD4+ T-cells in T-ASCs co-cultures was inhibited in the presence of HD/ ASCS and $\mathrm{HD} / \mathrm{ASCS}_{\mathrm{TI}}$ by $50.7 \pm 5.9 \%$ and $63.8 \pm 5.1 \%$, respectively, while AS/ASCS and AS/ASCS $\mathrm{AT}_{\mathrm{TI}}$ reduced it by $42.2 \pm 6.8 \%$ and $49.2 \pm 7.6 \%$, respectively (mean \pm SEM; data not shown).

However, as shown in Figure $1 \mathrm{~A}-\mathrm{C}$, there were no significant differences between inhibitory effects exerted by HD/ASCs and AS/ASCS on T-cell proliferation response, i.e. the percentage of proliferating cells, the proliferation, and replication indices. 

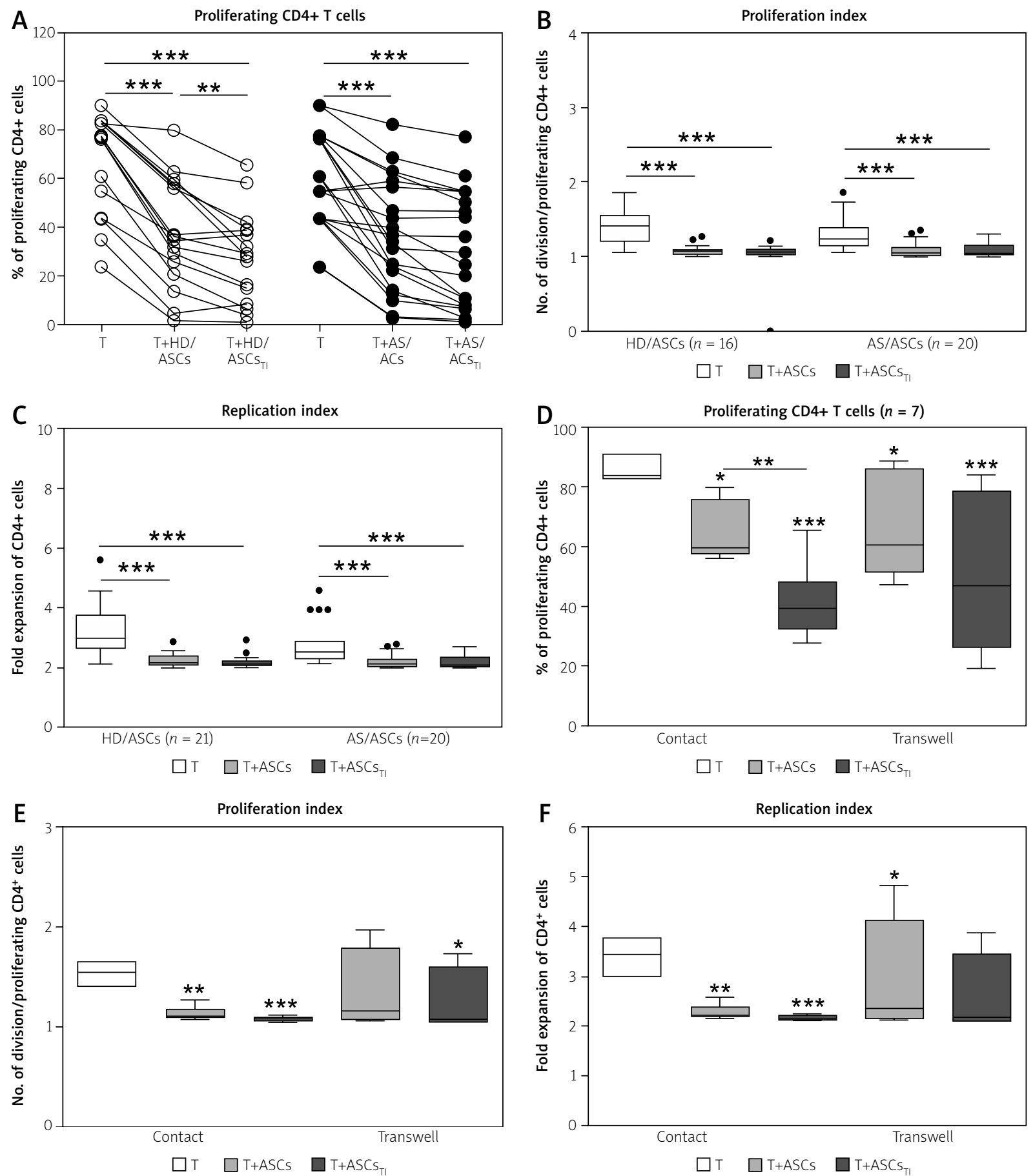

Fig. 1. Inhibition of T-cell proliferation by adipose-derived stem cells of healthy donors and ankylosing spondylitis patients. T helper (CD3+CD4+) lymphocytes, isolated from peripheral blood of $13(\mathrm{~A}-\mathrm{C})$ or $3(\mathrm{C}-\mathrm{F})$ healthy donors, were stimulated with anti-CD3/anti-CD28 antibodies and cultured alone (T) or co-cultured for 5 days with either untreated or TNF+IFN- $\gamma$ (TI)-stimulated ASCs from 5 HD (HD/ASCS) or 10 AS patients (AS/ASCS). The cell co-cultures were performed in conditions allowing direct cell contact $(\mathrm{A}-\mathrm{C})$ and in a transwell system (D-F, as indicated). Proliferation of CD4+ T-cells was analysed by flow cytometry. Data are the results of the indicated number of experiments $(n)$, performed using random combination of ASCs and T-cells. Upper panels $(A-C)$ - lines between points identify cultures containing the same combination of ASCs and T-cells. Lower panels (D-F) - results are expressed as the median (horizontal line) with interquartile range (IQR, box), lower and upper whiskers (data within $3 / 2 \times I Q R)$ and outliers (points) (Tukey's box). Values: ${ }^{*} p=0.05-0.01 ;{ }^{* *} p=0.01-0.001,{ }^{* * *} p=0.001-0.0001$ for intra-group comparisons. The inter-group (HD vS. AS and contact vs. transwell co-cultures) differences were statistically insignificant. 
Moreover, untreated and TI-treated AS/ASCs reduced T-cell proliferation to a similar extent, while TI-treated HD/ASCs were more potent than untreated HD/ASCs in diminishing the number of proliferating cells (Fig. 1A), but the reduction of $\mathrm{PI}$ and $\mathrm{RI}$ values by these cells was comparable (Figs. 1B and 1C).

\section{Contribution of cell-to-cell contact and soluble factors to anti-proliferative effect of adipose tissue-derived mesenchymal stem cells}

Results of co-culture of untreated and TI-treated HD/ASCs with CD4+ T lymphocytes in the conditions allowing or preventing (transwell) direct cell-to-cell contact showed that inhibition of T-cell proliferation did not differ significantly between these culture systems (Figs. 1D-F), although in transwell cultures more scattered data were obtained.

A

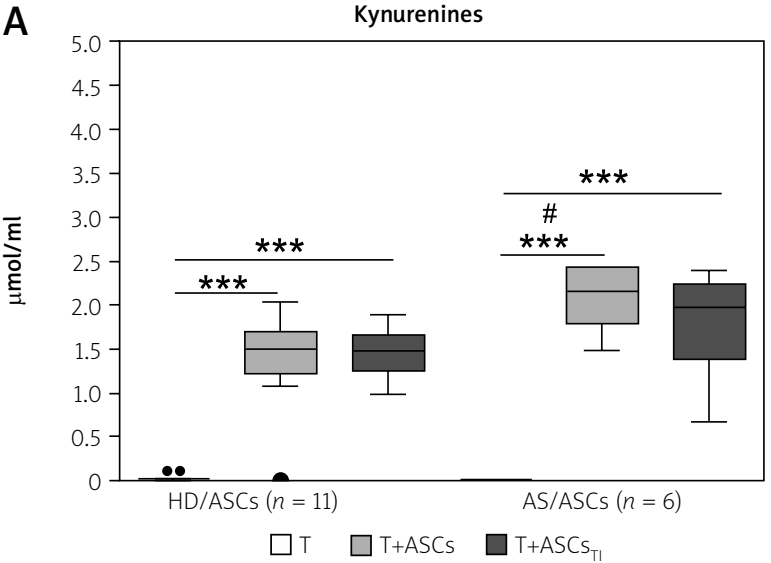

C

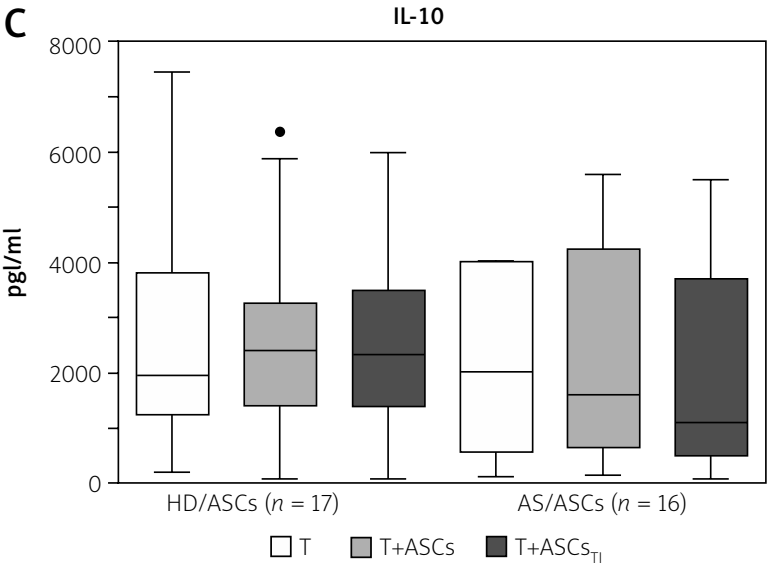

These results point to secretory factors as critical mediators of ASC-triggered anti-proliferative effects. Therefore, we further investigated the production of several soluble factors in ASC/CD4+ T-cell co-cultures.

\section{Production of soluble factors in co-cultures of $\mathrm{CD}^{+}{ }^{+}$-cells with adipose tissue-derived mesenchymal stem cells}

Untreated and activated CD4+T-cells produced small quantities of kynurenines (mean \pm SEM $=0.004 \pm 0.001$ vs. $0.05 \pm 0.02 \mathrm{mmol} / \mathrm{ml}, n=7, p=0.02$ for untreated vs. anti-CD3/CD28-stimulated T-cells) and PGE-2 (0 vs. $815 \pm 531 \mathrm{pg} / \mathrm{ml}, n=15, p=0.09$ for untreated vs. antiCD3/CD28-stimulated T-cells) (data not shown). In the co-cultures of activated CD4+ T-cells with HD/ASCs and AS/ASCs significant increases of kynurenines and PGE-2 production were observed and untreated and TI-treated ASCs exerted similar enhancing effects (Figs. 2A and 2B).
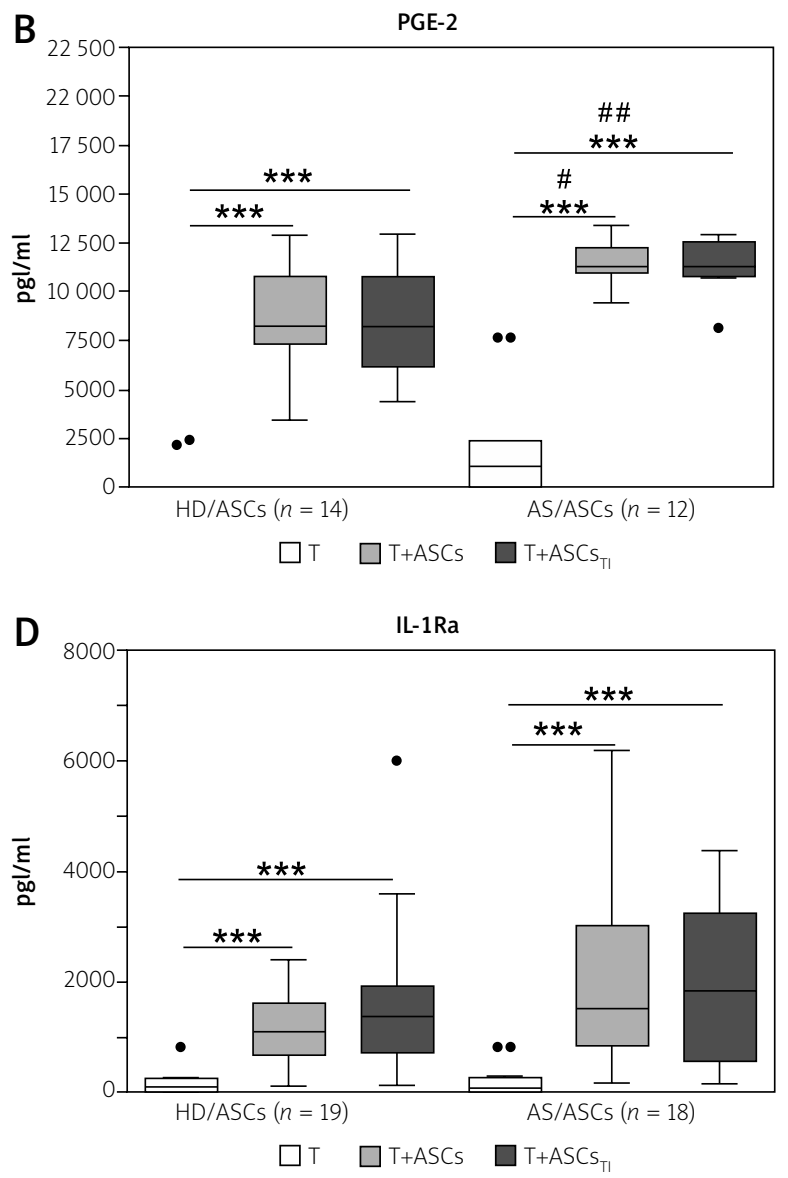

Fig. 2. Concentrations of soluble factors in the co-cultures of T-cells with adipose tissue-derived mesenchymal stem cells. Cells were prepared and co-cultured as described in Figure 1. CD4+ T-cells were isolated from peripheral blood of 10-17 healthy blood donors. Five HD/ASCs lines and AS/ASCs obtained from 6-8 patients were used. The concentrations of indicated soluble factors in culture supernatants were measured as described in the material and methods section. Data are the results of the indicated number of experiments $(n)$, performed using random combination of ASCs and T-cells, and are shown as Tukey's boxes. Values: ${ }^{* *} p=0.001-0.0001$ for intra-group (T vs. T+ASCs) comparisons; ${ }^{*} p=0.05-0.01,{ }^{\# \#} p=0.01-0.001$ for inter-group (HD vs. AS) comparison. 
A

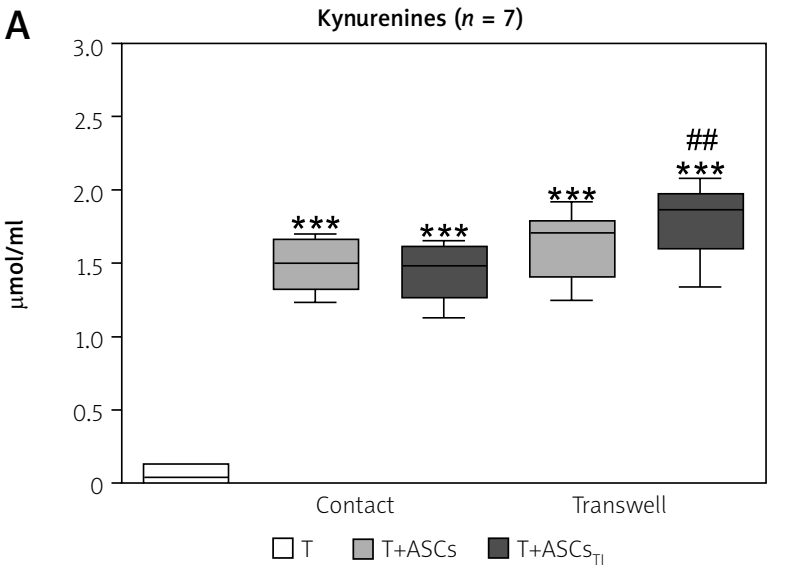

C

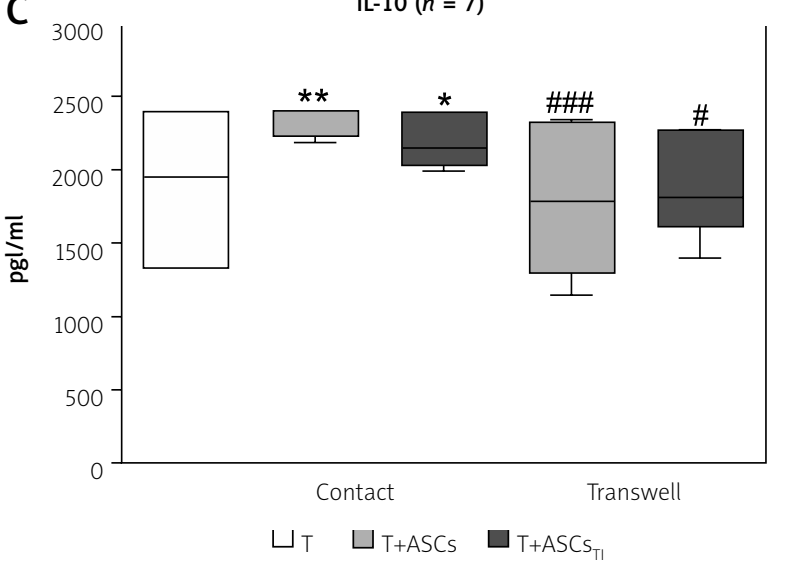

B

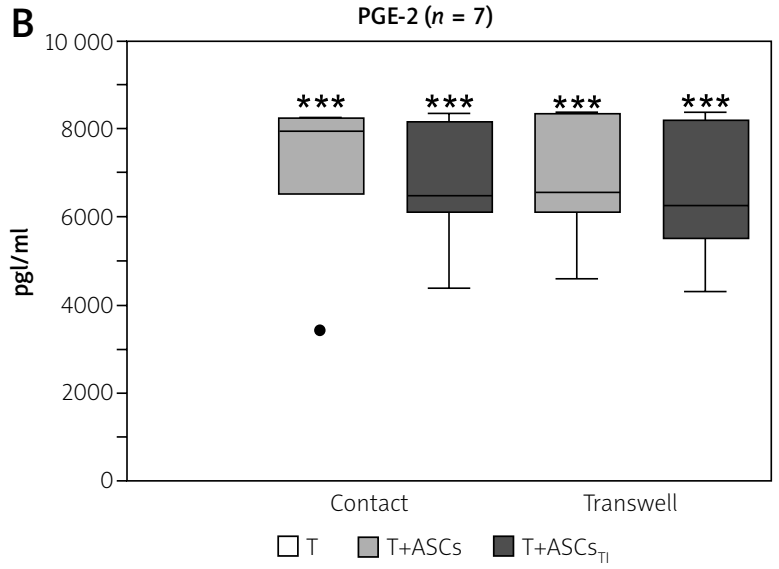

D

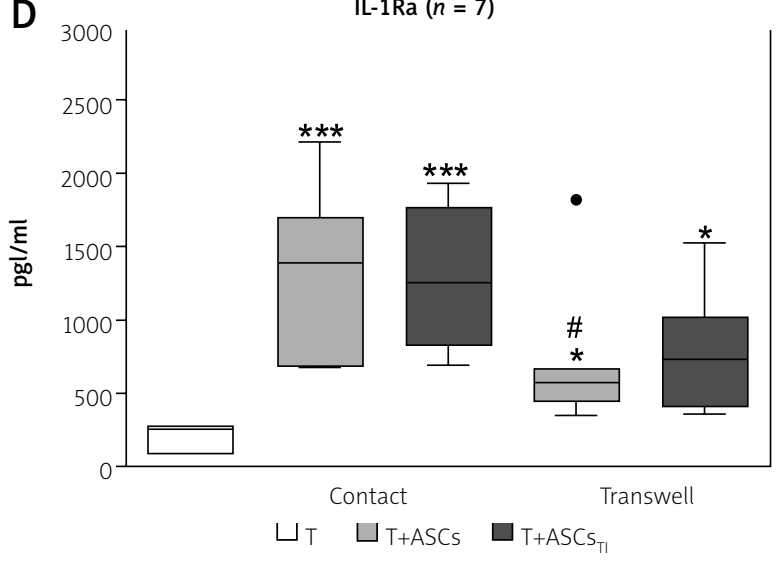

Fig. 3. Comparison of soluble factor production in contact and transwell co-cultures. Cells were prepared and co-cultured as described in Figure 1. Five HD/ASCs lines and CD4+ T-cells from peripheral blood of 5-7 healthy blood donors were used. The concentrations of indicated soluble factors in culture supernatants were measured as described in the material and methods section. Data are the results of the indicated number of experiments ( $n$ ), performed using random combination of ASCs and T-cells, and are shown as Tukey's boxes. Values: ${ }^{*} p=0.05-0.01,{ }^{* *} p=0.01-0.001,{ }^{* * *} p=0.001-0.0001$ for intra-group (T vs. T+ASCs)

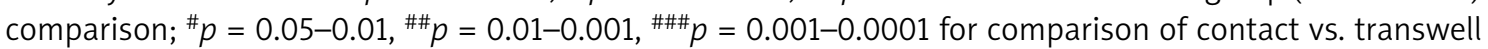
cultures.

Importantly, both untreated and TI-treated AS/ASCs induced higher secretion of these factors, especially PGE-2, than HD/ASCs (Figs. 2A and 2B).

In separate cultures, CD4+ T-cells activated via the CD3/CD28 pathway produced significantly more IL-10 and IL-1Ra than resting cells. The concentrations of these cytokines in the culture supernatants of resting versus activated T-cells (mean \pm SEM, $n=7$ ) were as follows: 0 vs. $1906 \pm 165 \mathrm{pg} / \mathrm{ml}, p=0.02$, for IL-10 and $70 \pm 33$ vs. $216 \pm 33 \mathrm{pg} / \mathrm{ml}, p=0.02$, for IL-1Ra. In the co-cultures of activated CD4+ T-cells with untreated and TI-treated HD/ASCs and AS/ASCs no significant changes were observed in the concentrations of IL-10 (Fig. 2C), while a significant and comparable increase of IL-1Ra levels was found in these conditions (Fig. 2D).

\section{Dependence of kynurenines, PGE-2, IL-10, and IL-1Ra production on cell-cell contact and soluble factors}

In the cell-to-cell contact and transwell co-cultures of CD4+ T-cells with HD/ASCs the concentrations of PGE-2 were similar (Fig. 3B), whereas kynurenines levels were higher in transwell than cell contacting co-cultures, especially in those containing TI-treated HD/ASCS (Fig. 3A). By contrast, the concentrations of IL-10 (Fig. 3C), and to a lesser extent also IL-1Ra, (Fig. 3D) were significantly lower in the transwell system than in cell contacting co-cultures.

Thus, these results indicate that in the co-cultures of purified CD4+ T-cells with HD/ASCs up-regulation of kynurenines and PGE-2 release is dependent mostly on 
Table II. Correlation between soluble factor concentrations and T-cell proliferation in co-cultures with adipose tissuederived mesenchymal stem cells

\begin{tabular}{|c|c|c|c|c|c|c|c|c|}
\hline \multirow[t]{2}{*}{ Factor } & \multirow[t]{2}{*}{$\begin{array}{c}\text { Type of } \\
\text { ASCs }\end{array}$} & \multirow[t]{2}{*}{$\begin{array}{c}\text { ASC activation } \\
\text { status }\end{array}$} & \multicolumn{2}{|c|}{$\begin{array}{c}\% \text { of proliferating CD4+ } \\
\text { T-cells }\end{array}$} & \multicolumn{2}{|c|}{$\begin{array}{l}\text { Proliferation } \\
\text { index }\end{array}$} & \multicolumn{2}{|c|}{$\begin{array}{l}\text { Replication } \\
\text { index }\end{array}$} \\
\hline & & & $\begin{array}{l}\text { Correlation } \\
\text { coefficient }\end{array}$ & $p$-value & $\begin{array}{l}\text { Correlation } \\
\text { coefficient }\end{array}$ & $p$-value & $\begin{array}{l}\text { Correlation } \\
\text { coefficient }\end{array}$ & $p$-value \\
\hline \multirow[t]{4}{*}{ Kynurenines } & \multirow{2}{*}{$\begin{array}{c}\mathrm{HD} / \mathrm{ASCS} \\
(n=8)\end{array}$} & Unstimulated & $R=0.334$ & 0.42 & $R=0.316$ & 0.44 & $R=0.325$ & 0.43 \\
\hline & & Ti-treated & $R=-0.370$ & 0.37 & $R=-0.655$ & 0.078 & $R=-0.652$ & 0.079 \\
\hline & \multirow{2}{*}{$\begin{array}{l}\text { AS/ASCS } \\
(n=8)\end{array}$} & Unstimulated & $R_{s}=-0.675$ & 0.069 & $R_{s}=-0.795$ & 0.022 & $R_{s}=-0.795$ & 0.022 \\
\hline & & Ti-treated & $R=-0.543$ & 0.164 & $R=-0.888$ & 0.003 & $R=-0.883$ & 0.004 \\
\hline \multirow[t]{4}{*}{ PGE-2 } & \multirow{2}{*}{$\begin{array}{c}\mathrm{HD} / \mathrm{ASCS} \\
(n=13)\end{array}$} & Unstimulated & $R=-0.676$ & 0.011 & $R=-0.339$ & 0.260 & $R=-0.222$ & 0.466 \\
\hline & & Ti-treated & $R=-0.606$ & 0.022 & $R=-0.156$ & 0.611 & $R=0.022$ & 0.942 \\
\hline & \multirow{2}{*}{$\begin{array}{c}\text { AS/ASCS } \\
(n=8)\end{array}$} & Unstimulated & $R=-0.333$ & 0.349 & $R=-0.479$ & 0.166 & $R=-0.479$ & 0.166 \\
\hline & & Ti-treated & $R=-0.370$ & 0.296 & $R=-0.685$ & 0.035 & $R=-0.685$ & 0.035 \\
\hline \multirow[t]{4}{*}{ IL-10 } & \multirow{2}{*}{$\begin{array}{l}\mathrm{HD} / \mathrm{ASCS} \\
(n=14)\end{array}$} & Unstimulated & $R=0.368$ & 0.195 & $R=0.158$ & 0.590 & $R=-0.250$ & 0.388 \\
\hline & & Ti-treated & $R=-0.237$ & 0.413 & $R=-0.270$ & 0.350 & $R=-0.539$ & 0.031 \\
\hline & \multirow{2}{*}{$\begin{array}{c}\text { AS/ASCS } \\
(n=14)\end{array}$} & Unstimulated & $R_{s}=0.134$ & 0.648 & $R_{s}=-0.495$ & 0.072 & $R_{s}=-0.495$ & 0.07 \\
\hline & & Ti-treated & $R_{s}=0.073$ & 0.805 & $R_{s}=-0.563$ & 0.036 & $R_{s}=-0.563$ & 0.036 \\
\hline \multirow[t]{4}{*}{ IL-1Ra } & \multirow{2}{*}{$\begin{array}{c}\mathrm{HD} / \mathrm{ASCS} \\
(n=16)\end{array}$} & Unstimulated & $R=0.091$ & 0.737 & $R=0.040$ & 0.883 & $R=-0.045$ & 0.867 \\
\hline & & Ti-treated & $R_{s}=-0.429$ & 0.097 & $R_{s}=-0.409$ & 0.116 & $R_{s}=-0.297$ & 0.264 \\
\hline & \multirow{2}{*}{$\begin{array}{c}\text { AS/ASCS } \\
(n=16)\end{array}$} & Unstimulated & $R=-0.273$ & 0.305 & $R=-0.355$ & 0.177 & $R=-0.353$ & 0.181 \\
\hline & & Tl-treated & $R=0.213$ & 0.428 & $R=-0.044$ & 0.872 & $R=-0.016$ & 0.955 \\
\hline
\end{tabular}

ASCs - adipose tissue-derived mesenchymal stem cells, AS/ASCS - ASCs from ankylosing spondylitis patients, HD/ASCS - ASCS from healthy donors, $n$-number of performed experiments, TI-treated-ASCs pre-stimulated with TNF+IFN- $\gamma$, $R$-Pearson's correlation coefficient, Rs - Spearman's rank correlation coefficient; $p$-values $<0.05$ and $<0.1$ are marked in bold and underlined font, respectively.

soluble factors, while cell-to-cell contact is important to raise IL-1Ra and to maintain IL-10 levels, respectively.

\section{Association of soluble factor secretion with anti-proliferative effect of adipose tissue-derived mesenchymal stem cells}

As shown in Table II, in the co-cultures containing untreated HD/ASCs or AS/ASCs the proliferative response of T-cells inversely correlated with the concentration of PGE-2 or kynurenines and IL-10, respectively. The association was more evident in the presence of TI-treated HD/ASC and AS/ASCs (Table II, Fig. 4).

There was a moderate to strong negative correlation between the replication index on the one hand, and the concentrations of kynurenines, PGE-2, and IL-10, but not IL-1Ra, on the other hand (Fig. 4).

However, in the presence of HD/ASCS ${ }_{T}$, the association between RI values and kynurenines levels did not reach statistical significance $(R=-0.652, p=0.079)$, and PGE-2 concentration inversely correlated with the percentage of proliferating T-cells but not with RI (Fig. 4, Table II).
In the case of $A S / \mathrm{ASCS}_{\mathrm{TI}}$-containing co-cultures an inverse correlation was also found between the proliferation index and the levels of soluble factors, such as kynurenines, PGE-2, and IL-10 (Table II).

\section{Discussion}

The anti-proliferative effects of MSCs on T-cells have been demonstrated in vitro and in vivo [10, 11, 20, 21]. It is well documented that to exert these effects MSCs act directly [22-24] or indirectly via engagement of intermediary cells $[25,26]$.

Unfortunately, it is unknown whether ASCS of AS patients have these capabilities preserved. Considering the contribution of T-cell activation and expansion to AS pathology [4-9], and taking into account possible therapeutic application of AS/ASCs [27], functional characterisation of these cells is urgently required.

We have previously found that in comparison with HD/ASCs, separately cultured untreated and TI-treated AS/ASCs secrete less kynurenines, more IL-1Ra, but comparable amounts of PGE-2 [16]. In addition, we have recently reported that AS/ASCS fail to downregu- 

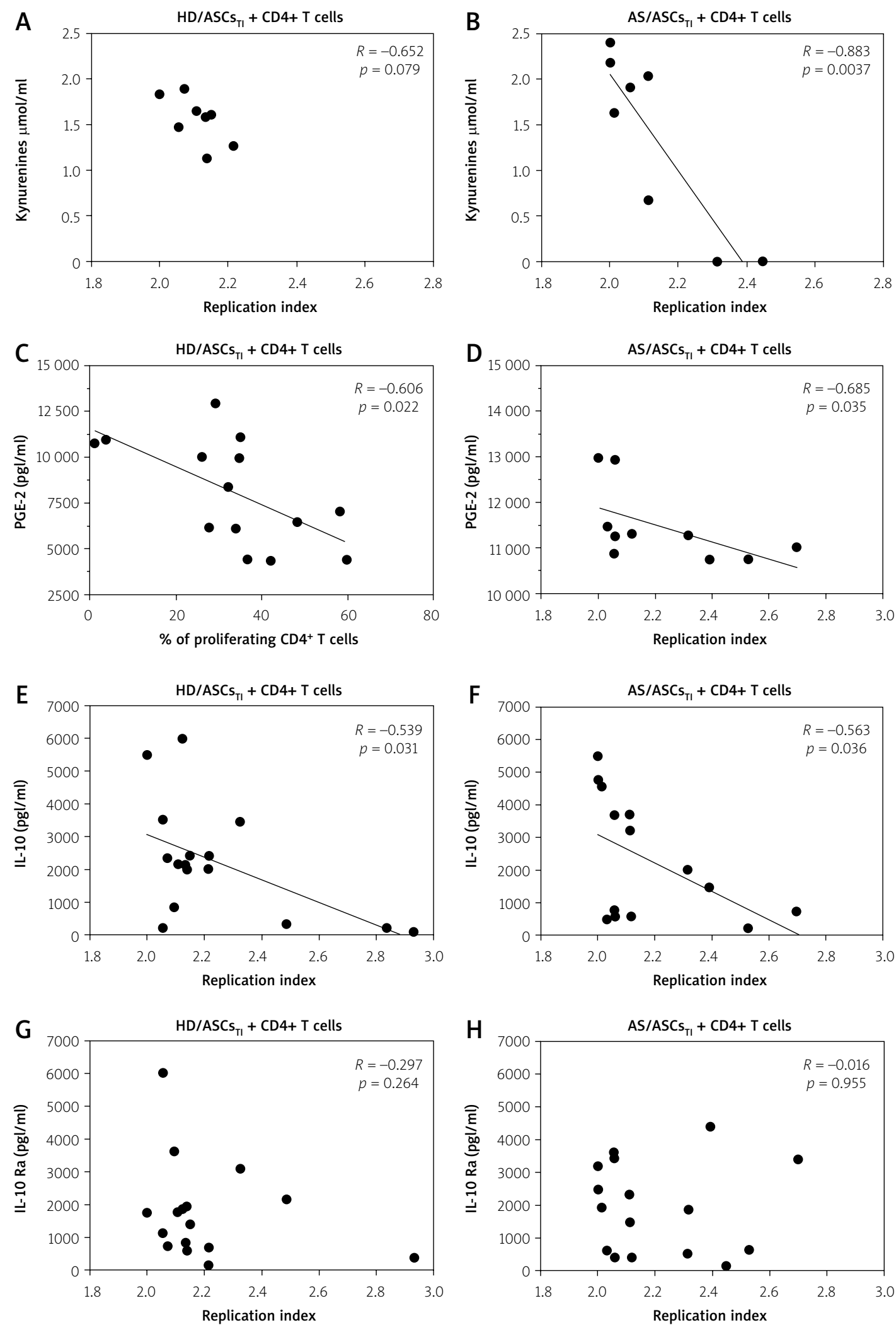

Fig. 4. Correlation between concentrations of soluble factors and T-cell proliferative response. Cell co-culture, the evaluation of T-cell proliferation, and measurement of indicated soluble factor concentrations were performed as described in the materials and methods section. Pearson's $(R)$ or Spearman's rank $\left(R_{s}\right)$ correlation coefficient and $p$-values are shown. Other explanations as in Figure 1. 
late a CD25 activation marker (IL-2 receptor a chain) on co-cultured CD4+ T-cells [28].

Despite these abnormalities, present results show that both HD/ASCs and AS/ASCs inhibit the proliferative response of purified allogeneic CD4+ T-cells with similar potency, reducing the number of proliferating cells, the number of divisions of these cells (PI), and their fold expansion over the culture time (RI) (Figs. 1A-C).

Thus, our results evidence normal anti-proliferative effects of AS/ASCS exerted on T helper (CD4+) cells in a direct manner. The immunomodulatory effects of MSCs are mediated by both direct cell-to-cell interactions and soluble factors $[10,11,29,30]$. Consistently with the reports of others [21,31,32], we have confirmed that the anti-proliferative effect of HD/ASCs is mediated mostly by soluble factors (Figs. 1D-F).

Because several soluble mediators, including kynurenines, PGE-2, and IL-10, have been reported to mediate the anti-proliferative effect of MSCs [31, 33], we also measured concentrations of these factors in co-culture supernatants. As shown in Figure 2, co-culture of CD4+ T-cells with ASCs significantly up-regulated the levels of kynurenines, PGE-2, and IL-1Ra, and the release of the first two factors was even higher in the co-cultures containing ASCs from AS patients than healthy donors.

By contrast, the concentration of $\mathrm{IL}-10$ did not change significantly (Fig. 2C). Because separately cultured ASCs [16] and activated CD4+ T-cells (see Results) produce small amounts of kynurenines, PGE-2, and IL-1Ra, it is clear that the significant, synergistic increase of production of these factors results from interactions of co-cultured ASCs and activated CD4+T-cells.

To verify whether these cell interactions depend on direct cell-to-cell contact or are mediated by soluble factors, the concentrations of kynurenines, PGE-2, IL-10, and IL-1Ra were also measured in contacting and noncontacting (transwell) co-culture systems (Fig. 3).

The obtained results show that HD/ASCs act by two distinct mechanisms. The first of these, which does not require cell-to-cell contact, up-regulates the release of PGE-2 and kynurenines (Figs. 3B and 3A, respectively). The second mechanism, which is contact dependent, controls anti-inflammatory cytokine levels, i.e. mediates IL-1Ra increase and maintenance of IL-10 levels.

Thus, our results regarding ASCs supplement the observations of others, showing the prominence of soluble factors in controlling kynurenine and PGE-2 production by various types of MSCs [31,33], and cell contact-dependent up-regulation of IL-10 gene expression in BM-MSCs [34].

Among tested factors, the kynurenine pathway and PGE-2 were reported to be critically involved in mediating anti-proliferative effects of various types of MSCs on T-cells, especially in humans [20, 31, 32, 35, 36].
In the first pathway, the essential amino acid tryptophan is metabolised by indoleamine 2,3-dioxygense (IDO) to kynurenines, and both local tryptophan deprivation and kynurenine accumulation result in the inhibition of T-cell proliferation [32, 37, 38]. Similarly, PGE-2 triggers cell cycle arrest of T-cells [25, 32, 36].

In addition, IL-10 can directly inhibit activation and proliferation of T-cells by altering the CD28 co-stimulation pathway [39]. Consistently with known anti-proliferative capabilities of the above factors, the present results show a significant, moderate to strong, inverse correlation between tested parameters of the T-cell proliferative response and the concentrations of kynurenines, PGE-2 and IL-10, especially in the co-cultures containing TI-pre-stimulated ASCs (Table II, Fig. 4). The priming of MSCs with pro-inflammatory cytokines, e.g. with TNF and/or IFN- $\gamma$, a procedure named "licensing", is known to enhance the immunosuppressive functions of these cells, including inhibition of T-cell proliferation [40].

Importantly, we observed that the association of the levels of soluble factors with T-cell proliferation was more evident in co-cultures containing TI-pre-stimulated ASCs of AS patients than healthy donors (Table II).

One possible explanation is significantly higher production of kynurenines and PGE-2 in the co-cultures of CD4+ T-cells with AS/ASCs than HD/ASCs (Figs. 2A and $2 B$ ). These observations suggest that AS/ASCs resemble, to a certain extent, in vivo "licensed" cells residing in chronically inflamed tissue.

As for the relationship between the proliferative response and IL-10, whose concentration was not affected by ASC presence, and was similar in co-cultures containing AS/ASCS and HD/ASCS, it is likely that the level of IL-10 receptor (IL-10R) expression on T-cells is important. It is known that the level of this cytokine receptor expression is closely dependent on T-cell activation, being very low on naïve while high on activated/memory cells, and thus regulates responsiveness of T-cells to IL-10 [41].

However, whether ASCs modulate IL-10R expression requires further investigations. By contrast to kynurenines, PGE-2, and IL-10, we did not observe any association of the concentration of IL-1Ra with the T-cell proliferative response (Table II, Fig. 4). This is consistent with the biological activity of IL-1Ra, which counteracts the pro-inflammatory effects of IL-1 and is a crucial mediator of MSCs-triggered immunosuppression of macrophages and B-cells, but does not affect CD4+ T-cell proliferation [42].

\section{Conclusions}

AS/ASCs similar to HD/ASCs also exert a direct effective anti-proliferative impact on CD4+ T-cells, acting 
via soluble factors that are released in cell contact-dependent (IL-10) and independent (kynurenines, PGE-2) pathways.

The results presented indicate that AS/ASC could be a potentially useful target for therapeutic applications.

The authors declare no conflict of interest.

Supported financially by the National Science Centre of Poland [grant number 2016/21/B/NZ5/00500] and by a core grant [grant number S/6] to the National Institute of Geriatrics, Rheumatology and Rehabilitation in Warsaw, from the Polish Ministry of Science and Higher Education.

\section{References}

1. Kontny E. New aspects of spondyloarthritis pathogenesis Part III - arthritis, pathological bone remodelling. Reumatologia 2014; 52: 247-254, DOI: 10.5114/reum.2014.44704.

2. Kontny E. New aspects of spondyloarthritis pathogenesis. Part I Genetic factors and role of HLA-B27 molecules. Reumatologia 2014; 52: 105-111, DOI: 10.5114/reum.2014.42795.

3. Liu $\mathrm{CH}$, Raj $\mathrm{S}$, Chen $\mathrm{CH}$, et al. HLA-B27-mediated activation of TNAP phosphatase promotes pathogenic syndesmophyte formation in ankylosing spondylitis. J Clin Invest 2019; 129 5357-5373, DOI: 10.1172/JCI125212.

4. Bollow M, Fischer T, Reißhauer $\mathrm{H}$, et al. Quantitative analyses of sacroiliac biopsies in spondyloarthropathies: T-cells and macrophages predominate in early and active sacroiliitis cellularity correlates with the degree of enhancement detected by magnetic resonance imaging. Ann Rheum Dis 2000; 59 : 135-140, DOI: 10.1136/ard.59.2.135.

5. Braun J, Bollow M, Neure L, et al. Use of immunohistologic and in situ hybridization techniques in the examination of sacroiliac joint biopsy specimens from patients with ankylosing spondylitis. Arthritis Rheum 1995; 38: 499-505, DOI: 10.1002/ art.1780380407.

6. Treviño MA, Teixeiro E, Bragado R. CD8+ T-cells oligoclonally expanded in synovial fluid at onset of spondyloarthropathy selectively proliferate in response to self-antigens: characterization of cell specificities in nonclonal populations. J Rheumatol 2004; 31: 1962-1972.

7. Bowness P, Ridley A, Shaw J, et al. Th17 cells expressing KIR3DL2+ and responsive to HLA-B27 homodimers are increased in ankylosing spondylitis. J Immunol 2011; 186: 2672 2680, DOI: 10.4049/jimmunol.1002653.

8. Wong-Baeza I, Ridley A, Shaw J, et al. KIR3DL2 binds to HLA-B27 dimers and free $\mathrm{H}$ chains more strongly than other HLA class I and promotes the expansion of T-cells in ankylosing spondylitis. J Immunol 2013; 190: 3216-3224, DOI: 10.4049/jimmunol. 1202926.

9. Šućur A, Jajić Z, Ikić Matijašević M, et al. Combined manual and automated immunophenotypisation identified diseasespecific peripheral blood immune subpopulations in rheumatoid arthritis, ankylosing spondylitis and psoriatic arthritis. Clin Exp Rheumatol 2020; 38: 903-916.
10. Cagliani J, Grande D, Molmenti EP, et al. Immunomodulation by mesenchymal stromal cells and their clinical application. J Stem Cell Regen Biol 2017; 3: 10.15436/2471-0598.17.022, DOI: 10.15436/2471-0598.17.022.

11. Duffy MM, Ritter T, Ceredig R, Griffin MD. Mesenchymal stem cell effects on T-cell effector pathways. Stem Cell Res Ther 2011; 2: 34, DOI: 10.1186/scrt75.

12. Petryk N, Shevchenko O. Mesenchymal stem cells anti-inflammatory activity in rats: proinflammatory cytokines. I Inflamm Res 2020; 13: 293-301, DOI: 10.2147/JIR.S256932.

13. LiX, Wang P, Xie Z, et al. Whole genome expression profiling and signal pathway screening of MSCs in ankylosing spondylitis. Stem Cells Int 2014; 2014: 913050, DOI: 10.1155/2014/913050.

14. Xie Z, Wang P, Li J, et al. MCP1 triggers monocyte dysfunctions during abnormal osteogenic differentiation of mesenchymal stem cells in ankylosing spondylitis. J Mol Med 2017; 95: 143154, DOI: 10.1007/s00109-016-1489-x.

15. Wu Y, Ren M, Yang R, et al. Reduced immunomodulation potential of bone marrow-derived mesenchymal stem cells induced CCR4+CCR6+ Th/Treg cell subset imbalance in ankylosing spondylitis. Arthritis Res Ther 2011; 13: R29, DOI: 10.1186/ar3257.

16. Kuca-Warnawin E, Skalska U, Janicka I, et al. The phenotype and secretory activity of adipose-derived mesenchymal stem cells (ASCs) of patients with rheumatic diseases. Cells 2019; 9: 1659, DOI: 10.3390/cells8121659.

17. Rudwaleit M, van der Heijde D, Landewé R, et al. The development of Assessment of SpondyloArthritis International Society classification criteria for axial spoandyloarthritis (part II): validation and final selection. Ann Rheum Dis 2009; 68: 777783, DOI: 10.1136/ard.2009.108233.

18. Skalska U, Kontny E, Prochorec-Sobieszek M, Maślinski W. Intra-articular adipose-derived mesenchymal stem cells from rheumatoid arthritis patients maintain the function of chondrogenic differentiation. Rheumatology (Oxford) 2012; 51: 17571764, DOI: 10.1099/rheumatology/kes129.

19. Roederer M. Interpretation of cellular proliferation data: avoid the panglossian. Cytometry A 2011; 79: 95-101, DOI: 10.1002/ cyto.a.21010.

20. Ahn JO, Chae JS, Coh YR, et al. Human adipose tissue-derived stem cells inhibit T-cell lymphoma growth in vitro and in vivo. Anticancer Res 2014; 34: 4839-4847.

21. Gao L, Liu F, Tan L, et al. The immunosuppressive properties of non-cultured dermal derived mesenchymal stromal cells and the control of graft-versus-host disease. Biomaterials 2014; 35: 3582-3588, DOI: 10.1016/j.biomaterials.2014.01.008.

22. Najar M, Raicevic G, Boufker HI, et al. Mesenchymal stromal cells use PGE-2 to modulate activation and proliferation of lymphocyte subsets: combined comparison of adipose tissue, Wharton's Jelly and bone marrow sources. Cell Immunol 2010; 264: 171-179, DOI: 10.1016/j.cellimm.2010.06.006.

23. Li $M$, Sun $X$, Kuang $X$, et al. Mesenchymal stem cells suppress CD8+ T cell-mediated activation by suppressing natural killer group 2, a member $\mathrm{D}$ protein receptor expression and secretion of prostaglandin E2, indoleamine 2,3-dioxygenase and transforming growth factor-b. Clin Exp Immunol 2014; 178: 516-524, DOI: 10.1111/cei.12423.

24. Yañez R, Oviedo A, Aldea M, et al. Prostaglandin E2 plays a key role in the immunosuppressive properties of adipose and bone 
marrow tissue-derived mesenchymal stromal cells. Exp Cell Res 2010; 316: 3109-3123, DOI: 10.1016/j.yexcr.2010.08.008.

25. Cutler AJ, Limbani V, Girdlestone J, Navarette CV. Umbilical cord-derived mesenchymal stromal cells modulate monocyte function to suppress T-cell proliferation. J Immunol 2010; 185 6617-6623, DOI: 10.4049/jimmunol.1002239.

26. Wang D, Chen K, Du WT, et al. CD14+ monocytes promote the immunosuppressive effect of human umbilical cord matrix stem cells. Exp Cell Res 2010; 316: 2414-2423, DOI: 10.1016/ j.yexcr.2010.04.018.

27. Bright B, Bright R, Bright P, Limaye A. Ankylosing spondylitis, chronic fatigue and depression improved after stromal vascular fraction treatment for osteoarthritis: a case report. J Med Case Rep 2018; 12: 238, DOI: 10.1186/s13256-018-1776-y.

28. Kuca-Warnawin E, Janicka I, Szczęsny P, et al. Modulation of T-cell activation markers expression by the adipose tissuederived mesenchymal stem cells of patients with rheumatic diseases. Cell Transplant 2020; 29: 1-13, DOI: 10.1177/096368 9720945682

29. Gao F, Chiu SM, Motan DA, et al. Mesenchymal stem cells and immunomodulation: current status and future prospects. Cell Death Dis 2016; 7: e2062, DOI: 10.1038/cddis.2015.327.

30. Zhou Y, Yamamoto Y, Xiao Z, Ochiya T. The immunomodulatory functions of mesenchymal stromal/stem cells mediated via paracrine activity. J Clin Med 2019; 8: 1025, DOI: 10.3390/ jcm8071025.

31. Menta R, Mancheño-Corvo P, Del Rio B, et al. Tryptophan concentration is the main mediator of the capacity of adipose mesenchymal stromal cells to inhibit T-lymphocyte proliferation in vitro. Cytotherapy 2014; 16: 1679-1691, DOI: 10.1016/ j.jcyt.2014.07.004.

32. Wang $X$, Wang $Y$, Zhou X, Liu F. Conditioned medium from adipose-derived stem cell inhibits Jurkat cell proliferation through TGF-b1 and p38/MAPK pathway. Analytical Cellular Pathology 2019; ID 2107414, DOI: 10.1155/2019/2107414.

33. DelaRosa O, Lombardo E, Beraza A, et al. Requirement of IFN-gamma-mediated indoleamine 2,3-dioxygenase expres- sion in the modulation of lymphocyte proliferation by human adipose-derived stem cells. Tissue Eng Part A 2009; 15: 27952806, DOI: 10. 1089/ten. TEA.2008.0630.

34. Nasef A, Chapel A, Mazurier C, et al. Identification of IL-10 and TGFb transcripts involved in the inhibition of T-lymphocyte proliferation during cell contact with human mesenchymal stem cells. Gene Expression 2007; 13: 217-226, DOI: 10.3727/000000006780666957.

35. Mellor AL, Munn DH. Tryptophan catabolism and regulation of adaptive immunity. J Immunol 2003; 170: 5809-5813, DOI: 10.4049/jimmunol.170.12.5809.

36. Yañez R, Oviedo A, Aldea M, et al. Prostaglandin E2 plays a key role in the immunosuppressive properties of adipose and bone marrow tissue-derived mesenchymal stromal cells. Exp Cell Res 2010; 316: 3109-3123, DOI: 10.1016./j.yexcr.2010.08.008.

37. Mándi Y, Vécsei, L. The kynurenine system and immunoregulation. J Neural Transm (Vienna) 2012; 119: 197-209, DOI: 10.1007/ s00702-011-0681-y.

38. Sreeramkumar V, Fresno M, Cuesta N. Prostaglandin E2 and T-cells: friends or foes? Immunol Cell Biol 2012; 90: 579-586, DOI: 10.1038/icb.2011.75.

39. Joss A, Akdis M, Faith A, et al. IL-10 directly acts on T-cells by specifically altering the CD28 co-stimulation pathway. Eur I Immunol 2000; 30: 1683-1690, DOI: 10.1002/1521-4141(200006)30:6<1683: :AID-IMMU1683>3.0.CO;2-A.

40. Seo Y, Shin TH, Kim HS. Current strategies to enhance adipose stem cell function: an update. Int J Mol Sci 2019; 20: 3827, DOI: 10.3390/ijms20153827.

41. Bedke T, Muscate F, Soukou S, et al. IL-10-producing T-cells and their dual functions. Semin Immunol 2019; 44: 101335, DOI: 10.1016/j.smim.2019.101335.

42. Luz-Crawford P, Djouad F. Mesenchymal stem cell-derived interleukin 1 receptor antagonist promotes macrophage polarization and inhibits B-cell differentiation. Stem Cells 2016; 34 : 483-492, DOI: 10.1002/stem.2254. 